\title{
Urinary Metabolic Profile of Patients with Transfusion-Dependent $\beta$-Thalassemia Major Undergoing Deferasirox Therapy
}

\author{
Giovanna Capolongo $^{a}$ Miriam Zacchia $^{a}$ Amerigo Beneduci $^{b}$ \\ Silvia Costantini ${ }^{c}$ Patrizia Cinque ${ }^{c}$ Anna Spasiano $^{c}$

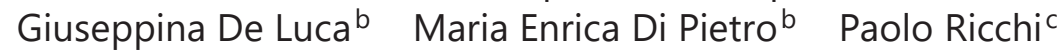 \\ Francesco Trepiccione $^{a, d}$ Giovambattista Capasso ${ }^{a, d} \quad$ Aldo Filosa $^{c}$ \\ aDepartment of Translational Medical Sciences, University of Campania "Luigi Vanvitelli", \\ Naples, Italy; ${ }^{b}$ Department of Chemistry and Chemical Technologies, University of Calabria, \\ Arcavacata di Rende (CS), Italy; ${ }^{c}$ Rare Blood Cell Disease Unit, "Cardarelli" Hospital, Naples,

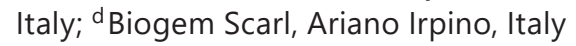

\section{Keywords}

$\beta$-Thalassemia major · Metabolomics · Urinomics · Tubular function · Renal disease

\begin{abstract}
Introduction: Renal dysfunction is a frequent complication in patients suffering from $\beta$-thalassemia major ( $\beta$-TM). The aim of this study was to analyze the renal function and urine metabolomic profile of $\beta$-TM patients undergoing transfusions and deferasirox (DFX) therapy, in order to better characterize and shed light on the pathogenesis of renal disease in this setting. Methods and Subjects: 40 patients affected by $\beta$-TM treated with DFX and 35 age- and gender-matched healthy controls were enrolled in the study. Renal function was assessed. Glomerular filtration rate (GFR) was estimated with CKD-EPI and Schwartz formula for adults and children, respectively. Renal tubular function and maximal urine concentration ability were tested. Urine specimens were analyzed by nuclear magnetic resonance spectroscopy to identify the urinary metabolite profiles. Results: The study of renal function in $\beta$-TM patients revealed normal estimated (e)GFR mean values and the albumin-to-creatinine ratio was $<30$ $\mathrm{mg} / \mathrm{g}$. The analysis of tubular function showed normal basal plasma electrolyte levels; $60 \%$ of patients presented hypercalciuria and many subjects showed defective urine concentration. Several amino acids, N-methyl compounds, and organic acids were overexcreted in the urine of thalassemic patients compared with controls. Discussion: The major finding of this work is that $\beta$-TM patients and controls exhibit different concentrations of some metabolites in the urine. Early recognition of urinary abnormalities may be useful to detect and prevent kidney damage.




\section{Kidney \\ Blood Pressure \\ Research}

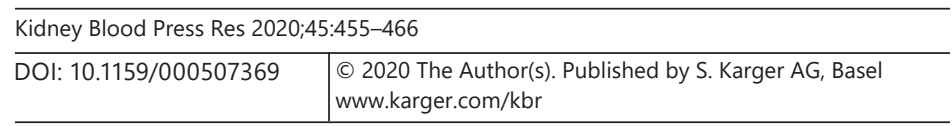

Capolongo et al.: Urinary Metabolomics in $\beta$-TM

\section{Introduction}

$\beta$-Thalassemia major ( $\beta$-TM) is an inherited disorder characterized by chronic hemolysis and inefficient erythropoiesis due to defective synthesis of $\beta$-globin chains. Periodic blood transfusion with units of packed red blood cells every 2 or 3 weeks is the milestone of treatment and is required to maintain pretransfusion hemoglobin levels between 9.5 and $10.5 \mathrm{~g} / \mathrm{dL}$ to ensure tissue oxygenation [1]. Even if the blood transfusion is life-saving, it is encumbered by a number of complications due to iron overload, e.g., hypogonadism, hypothyroidism, hypoparathyroidism, diabetes, renal and/or cardiac dysfunction, heart failure, and infections, especially in patients who have undergone splenectomy [2,3]. Success in the management of the transfusion-dependent thalassemia patients is related to an optimal chelation therapy to prevent organ damage. To date, 3 chelators (deferiprone [DFP], desferrioxamine [DFO], and deferasirox [DFX]) are available for treating thalassemia patients, and each presents efficacy and safety but also side effects. The negative balance between iron intake and iron output is the goal for improving survival [1].

There is evidence of renal dysfunction in $\beta$-TM patients. Signs of proximal tubular damage, like low-molecular-weight proteinuria, have been described in several reports [4-6]. Piga et al. [7] reported a normal glomerular filtration rate (GFR) measured by ${ }^{51} \mathrm{Cr}$-EDTA in patients with $\beta$-TM naïve to iron-chelating therapy with DFX. Treatment with DFX for up to 2 years was associated with reduction in GFR of 17.7-17.2\%, which did not progress during 2 years of follow-up and reversed after a 4-week washout period.

Additional studies have reported other signs of renal tubular dysfunction, including hypercalciuria, in $\beta$-TM patients on DFX, but this has not been examined systematically [7-9]. Wong et al. [10] reported that deferasirox at therapeutic doses leads to exacerbation of hypercalciuria in a dose-dependent manner and requires vigilance for osteoporosis, urolithiasis, and other markers of renal dysfunction.

$\beta$-TM patients showed also significantly higher levels of cystatin $C$, a sensitive marker of glomerular dysfunction and an early sign of renal impairment [11-13]. Finally, in $\beta$-TM patients, renal involvement encompasses tumorigenesis and cyst development, but for both of these, the underlying molecular basis has been hypothesized but not elucidated $[13,14]$.

The principal aim of this study was to analyze the spectrum of urine metabolites to verify if there are metabolic patterns that discriminate $\beta$-TM patients undergoing transfusion and chelation therapy with DFX from normal subjects.

\section{Materials and Methods}

\section{Patient Recruitment and Renal Function Analysis}

One hundred and eighty-five $\beta$-TM patients were admitted to the Rare Red Blood Cell Disease Unit, Cardarelli Hospital, Naples, Italy, and treated with regular and periodic transfusion of packed red blood cells every 2 weeks and chelation therapy with different chelators, i.e., DFP, DFO, and DFX.

Inclusion criteria included: a genetic diagnosis of $\beta$-TM, an age of $>8$ years, and DFX treatment for $>12$ months. Exclusion criteria included: an estimated (e)GFR $<60 \mathrm{~mL} /$ $\min / 1.73 \mathrm{~m}^{2}$, impaired liver function, pregnancy, and breastfeeding. Finally, $40 \beta$-TM patients that met the inclusion criteria were enrolled and 35 age- and gender-matched healthy individuals were selected as controls. Inclusion criteria for the control group included: normal renal function (eGFR $>90 \mathrm{~mL} / \mathrm{min} / 1.73 \mathrm{~m}^{2}$ ) and no anemia or history of chelation. Exclusion criteria included: impaired liver function, pregnancy, and breastfeeding. 


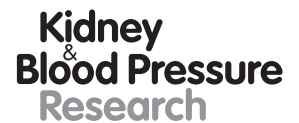

Kidney
Blood Pressure
Research

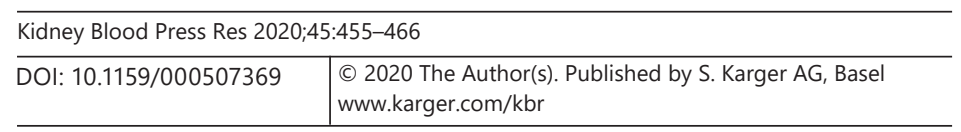

Capolongo et al.: Urinary Metabolomics in $\beta$-TM

Hematological and biochemical screening included: a complete blood count, liver and kidney function tests, fasting blood sugar, lipid profile, and serum ferritin. All participants collected a 24-h urine sample and the urine was kept refrigerated during the collection. Renal function was assessed in terms of the following:

- eGFR was calculated with CKD-EPI and the Schwartz formula for adults and children, respectively, using calibrated, standardized plasma creatinine measurement; the albumin-to-creatinine ratio (ACR) was measured;

- Tubular function was evaluated by arterial blood gas analysis, plasma electrolyte measurements, and determination of the fractional excretion of sodium $\left(\mathrm{FE}_{\mathrm{Na}}\right)$, calcium, bicarbonate, and phosphate. Maximal urine concentration ability was assessed by measuring urine osmolality after night (12-h) fluid restriction as done previously [15]. Fasting urine $\mathrm{pH}$ was measured using a standard $\mathrm{pH}$ meter [16]. Urinary bicarbonate was evaluated by acid base titration according to previous studies $[17,18]$.

\section{Definitions}

The diagnosis of $\beta$-TM was based on the genetic characterization of $\alpha$-globin and $\beta$-globin chains to identify the genetic defect underlying the disease. eGFR and ACR were classified based on K-DIGO 2012 guidelines [19]; urine calcium-to-creatinine ratio was defined as normal or high $(<0.2$ and $>0.2$, respectively). Defective urine concentration was considered as having a maximum urine osmolality $<750 \mathrm{mOsm} / \mathrm{kg}$ of water for adults and $<600 \mathrm{mOsm} / \mathrm{kg}$ of water for children (aged $<16$ years) after $12 \mathrm{~h}$ of fluid restriction. Metabolic acidosis was defined as bicarbonate plasma levels $<22 \mathrm{mmol} / \mathrm{L}$ on arterial blood gas analysis.

\section{Experimental Protocol}

Urine specimens were analyzed by nuclear magnetic resonance spectral acquisition (NMR spectroscopy) to discover differences in the urinary metabolite profiles between cases and controls. Sample pretreatment for NMR observation was performed by:

1. Adjusting the $\mathrm{pH}$ to $1.2-2$ as already reported previously [20, 21]. Briefly, $50 \mu \mathrm{L}$ of urine was mixed with $50 \mu \mathrm{L}$ of $4.85 \mathrm{~mm}$ standard solution of sodium-3-trimethylsilyl[2,2,3,3-2 $\left.{ }^{2} \mathrm{H}_{4}\right]$-propionate (TSP; Sigma-Aldrich) in $\mathrm{D}_{2} \mathrm{O}$ (99.9\%; Avanti Polar Liquids). The $\mathrm{pH}$ value was adjusted to $1.2 \leq \mathrm{pH} \leq 2$ by adding $50 \mu \mathrm{L}$ of $3-\mathrm{M} \mathrm{HCl}$ solution. Final $\mathrm{pH}$ was monitored by inspection of citrate signals (always detected in all samples) [20-22].

2. Adjusting the $\mathrm{pH}$ to neutral with the addition of a phosphate buffer, as described in the literature. $550 \mu \mathrm{L}$ of urine were mixed with $50 \mu \mathrm{L}$ of a $1 \mathrm{M}$ potassium sodium buffer $\mathrm{D}_{2} \mathrm{O}$ solution with $\mathrm{K}_{2} \mathrm{HPO}_{4}$ and $\mathrm{NaH}_{2} \mathrm{PO}_{4} \times 2 \mathrm{H}_{2} \mathrm{O}$ containing TSP at a concentration of $0.05 \%$ $(\mathrm{m} / \mathrm{v})[23,24]$.

The urine specimens were then transferred into a 5-mm NMR tube for spectral acquisition. Spectra were acquired on a Bruker Avance 500 spectrometer (500-MHz proton resonance), at $298 \mathrm{~K}$ and at a spinning frequency of $20 \mathrm{~Hz}$, by locking the spectrometer field using the deuterium resonance provided by the $\mathrm{D}_{2} \mathrm{O}$ used in the preparation of the urine sample. In order to suppress the intense water peak, the presaturation pulse sequence zgpr (Bruker Biospin) was used. The optimized acquisition parameters were: a $90^{\circ}$ pulse of $12 \mu \mathrm{s}$; a spectral width of 12 ppm for all data collection, and typically 128 FIDs were accumulated for the analysis into 64-K digital data points; and a 4-s delay time between pulses. All collected FIDs were apodized prior to Fourier transform, with an exponential decay corresponding to a line broadening of $0.4 \mathrm{~Hz}$. Spectra were zero-filled to $128 \mathrm{~K}$.

TSP was taken as a qualitative standard for chemical shift scale $(0.015 \mathrm{ppm})$ as well as a quantitative internal standard for peak area calculation. Standard metabolites solutions, at the specified $\mathrm{pH}$ values, were used for the assignment of the chemical shift of each 
Table 1. Demographic and anthropometric characteristics and markers of renal and tubular function of study groups

\begin{tabular}{|c|c|c|c|}
\hline & $\begin{array}{l}\beta \text {-TM patients } \\
(n=40)\end{array}$ & $\begin{array}{l}\text { Controls } \\
(n=35)\end{array}$ & $p$ value $^{\mathrm{b}}$ \\
\hline Age, years & $34 \pm 12$ & $33 \pm 14$ & 0.85 \\
\hline BMI & $22.9 \pm 3.5$ & $23.8 \pm 1.2$ & 0.23 \\
\hline Serum creatinine, mg/dL & $0.74 \pm 0.21$ & $0.71 \pm 0.13$ & 0.39 \\
\hline $\mathrm{eGFR}, \mathrm{mL} / \mathrm{min} / 1.73 \mathrm{~m}^{2}$ & $109.5 \pm 18$ & $112 \pm 12$ & 0.52 \\
\hline Hemoglobin, g/dL & $9.8 \pm 0.4$ & $13.2 \pm 1.4$ & $<0.001$ \\
\hline Ferritin, ng/mL & $1,559 \pm 583$ & $150 \pm 22$ & $<0.001$ \\
\hline \multicolumn{4}{|l|}{ Serum concentrations } \\
\hline Sodium, mmol/L & $142 \pm 3$ & $139 \pm 3$ & $<0.001$ \\
\hline Potassium, mmol/L & $4.53 \pm 0.44$ & $4.06 \pm 0.4$ & $<0.001$ \\
\hline Calcium, mg/dL & $9.5 \pm 0.6$ & $9.2 \pm 0.8$ & 0.19 \\
\hline Chlorine, mmol/L & $104 \pm 2$ & $101 \pm 3$ & 0.78 \\
\hline Bicarbonate & $27.8 \pm 5.8$ & $28 \pm 4.6$ & 0.72 \\
\hline $\mathrm{Fe}_{\mathrm{Na}}, \%$ & $0.93 \pm 0.45$ & $0.98 \pm 0.9$ & 0.64 \\
\hline \multicolumn{4}{|l|}{ Urinary values } \\
\hline Calcium, mg/24 h & $398 \pm 172$ & $180 \pm 62$ & $<0.001$ \\
\hline Phosphorus, mg/24 h & $835 \pm 364$ & $895 \pm 492$ & 0.8 \\
\hline ACR, mg/g & $18.7 \pm 8.8$ & $16.9 \pm 7.9$ & 0.15 \\
\hline Osmolarity ${ }^{\mathrm{a}}$ (subjects $<16$ years), $\mathrm{mOsm} / \mathrm{kg}$ & $546 \pm 117$ & $817 \pm 137$ & $<0.001$ \\
\hline Osmolarity $^{\text {a }}$ (subjects $>16$ years), $\mathrm{mOsm} / \mathrm{kg}$ & $669 \pm 243$ & $900 \pm 235$ & $<0.001$ \\
\hline $\mathrm{pH}$ & $5.9 \pm 0.8$ & $6.1 \pm 0.6$ & 0.26 \\
\hline
\end{tabular}

Values are reported as mean \pm standard deviation. $\beta$-TM, beta-thalassemia; $\mathrm{Fe}_{\mathrm{Na}}$, urinary excretion fraction of sodium; ACR, albumin-to-creatinine ratio.

${ }^{a}$ Urinary osmolarity after $12 \mathrm{~h}$ of fluid restriction.

b Mann-Whitney U test.

spectral signal. Metabolite concentration (mmol/L), was calculated according to the following equation, by measuring the height of the selected peak representative for the metabolite " $h$ ":

$$
[\text { Metabolite }]=\frac{h(\text { metabolite })[T S P]}{h(\text { TSP })} f
$$

where $h(T S P)$ is the height of the standard TSP peak, [TSP] is the molar concentration of TSP added, and $f$ is a factor accounting for the number of hydrogens and the multiplicity of the signal of the TSP peak and of the signal to which the selected metabolite peak belongs.

Metabolite quantification was also expressed as $\mathrm{mmol} / \mathrm{mol}$ of creatinine by normalizing with respect to the creatinine peak height, $h(\mathrm{Cre})$, according to the following equation:

$$
[\text { Metabolite }]=\frac{h(\text { metabolite })}{h(\text { Cre })} f
$$

Untargeted Metabolomic Analysis across the Full Spectral Range

For metabolomic analysis, all the spectra were bucketed with bins of either 0.04 or 0.01 ppm. Bucketing was performed by the MNOVA software. The bucketed spectra were normalized with respect to the total spectral area. The following spectral regions were excluded from the analysis: $0-0.5,4.8-5.5$, and $>10.5 \mathrm{ppm}$, resulting in bucketed spectra with 249 and 1,000 variables, respectively, for the 0.04 - and 0.01 -ppm binning.

The bucketed spectra were imported in SIMCA-P13 (Umetrics) for multivariate data analysis. As a first step, an exploratory multivariate analysis was performed with principal 
Fig. 1. Three-dimensional scores scatter-plot of the first 3 principal components. Blue dots, healthy individuals; green dots, thalassemic patients.

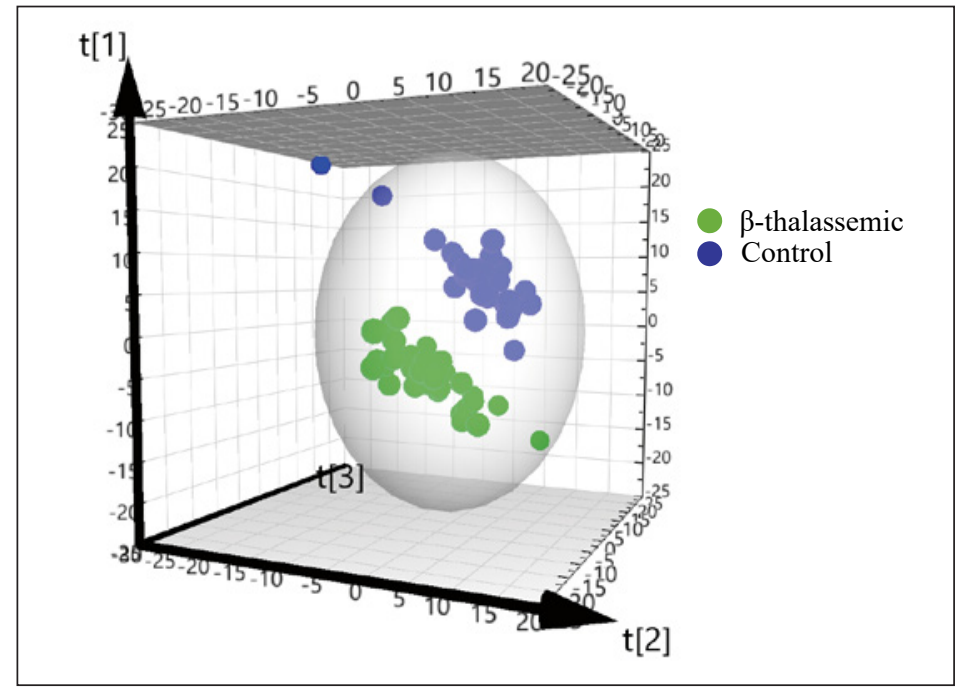

components analysis (PCA), on data preprocessed by unit variance scaling (UV) and mean centering. Then, a partial least-squares discriminant analysis (PLS-DA) was used to find the principal components best describing class separation. Each class is defined by a matrix of response variables reporting the class membership of each observation in the training dataset. PLS-DA provides the correlation between the response variables and the observations.

\section{Statistical Analysis}

Comparisons between $\beta$-TM cases and controls were performed by the goodness-of-fit test. Since some of the variables were not found to be normally distributed, the Mann-Whitney $\mathrm{U}$ test was used to test differences between means.

\section{Results}

\section{Renal and Tubular Function}

Demographic and anthropometric characteristics and other markers of renal and tubular function of $\beta$-TM subjects and controls are shown in Table 1.

In the $\beta$-TM group, mean eGFR was $109.6 \mathrm{~mL} / \mathrm{min} / 1.73 \mathrm{~m}^{2} ; 80 \%$ of patients had an eGFR $>90$ and $20 \%$ had $60-90 \mathrm{~mL} / \mathrm{min} / 1.73 \mathrm{~m}^{2}$. ACR was $<30 \mathrm{mg} / \mathrm{g}$ in all patients. The analysis of tubular function revealed normal basal plasma electrolyte levels, with basal $\mathrm{Fe}_{\mathrm{Na}}<1 \%$ in most of the patients, as in the normal range [47]; the mean fractional bicarbonate excretion $\left(\mathrm{FeHCO}_{3}\right)$ was $<1 \%$ and no difference in urinary excretion of bicarbonate/creatinine and $\mathrm{FeHCO}_{3}$ was detected between study groups. $60 \%$ of patients showed hypercalciuria in the absence of hypercalcemia. In adults, the mean maximal urine osmolality was $669 \mathrm{mOsm} / \mathrm{kg}$, with $50 \%$ showing a defective ability to concentrate the urine, defined as a urine osmolality $<750 \mathrm{mOsm} / \mathrm{kg}$ (an arbitrary cut-off based on the literature) [25, 26]. After overnight fasting, urine $\mathrm{pH}$ was $>6.5$ in $20 \%$ of the patients analyzed, and $>80 \%$ of patients had a urine $\alpha_{1^{-}}$ microglobulin concentration $>15 \mathrm{mg} / \mathrm{g}$ creatinine, indicating defective tubular reabsorption.

\section{Urine Metabolomic Profile in Patients and Controls}

After explorative PCA, PLS-DA was performed with the aim of distinguishing between the thalassemic and healthy individuals. The resulting statistical models obtained with the 2 sets of binned spectra $(0.04$ and $0.01 \mathrm{ppm})$ were very robust with R2 and Q2 always $>0.5$. 

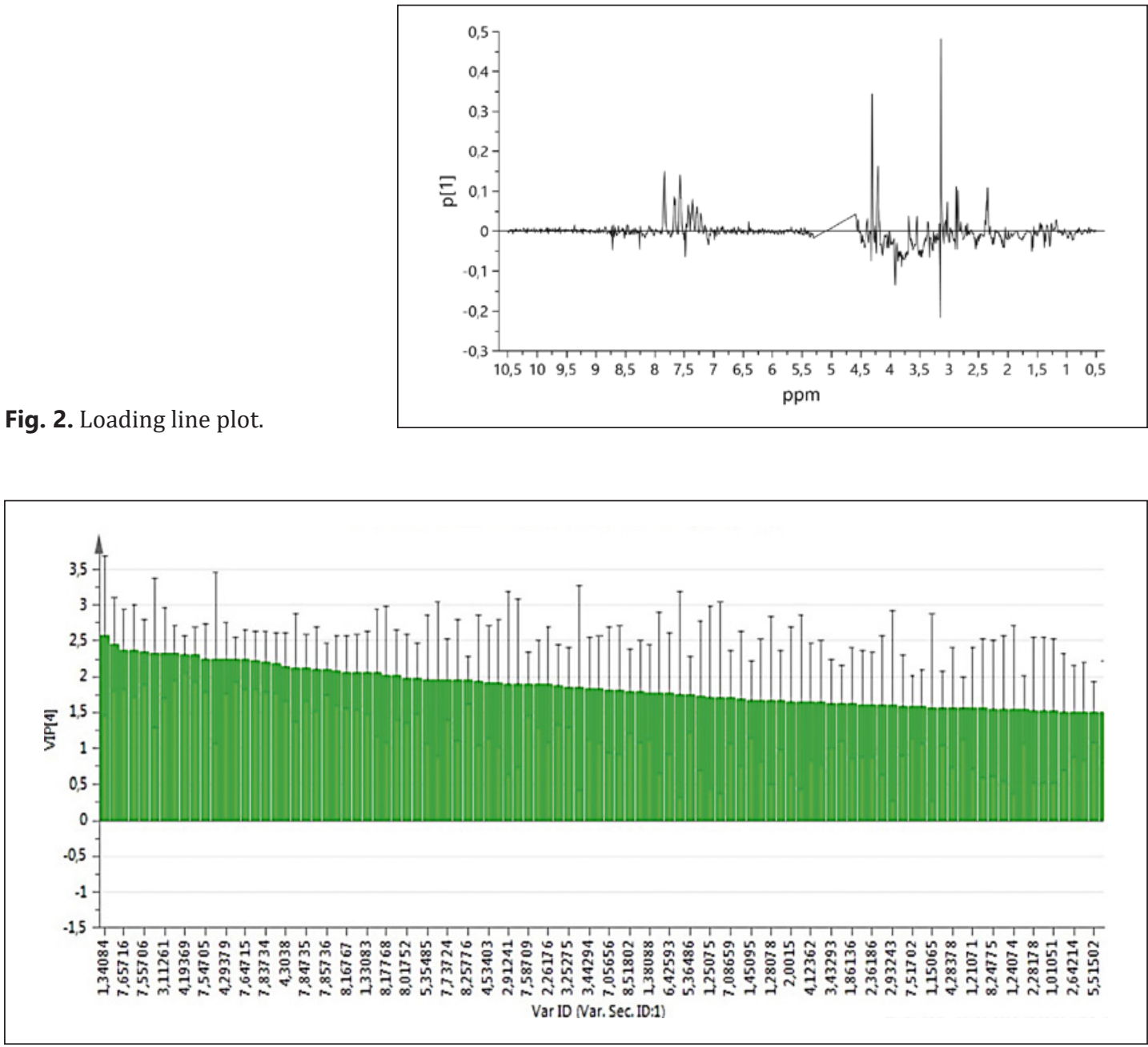

Fig. 3. VIP plot of the first 100 variables. Variables with a VIP value $>1$ are considered "important."

We discuss the analysis of the 0.01-ppm binned spectra, which gave the best results, in online supplementary Figure 1 (see www.karger.com/doi/10.1159/000507369 for all online suppl. material).

The scatter-plot scores of the first 3 principal components, accounting for $>80 \%$ of the variance, are reported in Figure 1. The inspection of this plot highlights a clear distinction between the healthy individuals (blue dots) and the $\beta$-TM patients (green dots), indicating that these 2 populations have significantly different metabolite profiles.

In order to understand the distinctive metabolic differences between the 2 groups, analysis of the loadings was performed. In an untargeted metabolomic analysis, the PLS loadings line-plot across the full spectral range is better-suited to detecting spectral regions where differences occur, i.e., that mainly contributed to the discrimination between the thalassemic and healthy individuals. As reported in Figure 2, the chemical shift regions, where significant differences occurred, are those at 1-4 and 7-8 ppm.

This is further confirmed in Figure 3 where the variables importance plot (VIP) is displayed. It shows that the most important variables (chemical shift spectral regions) that are able to discriminate between thalassemic and healthy individuals are those specified above. 


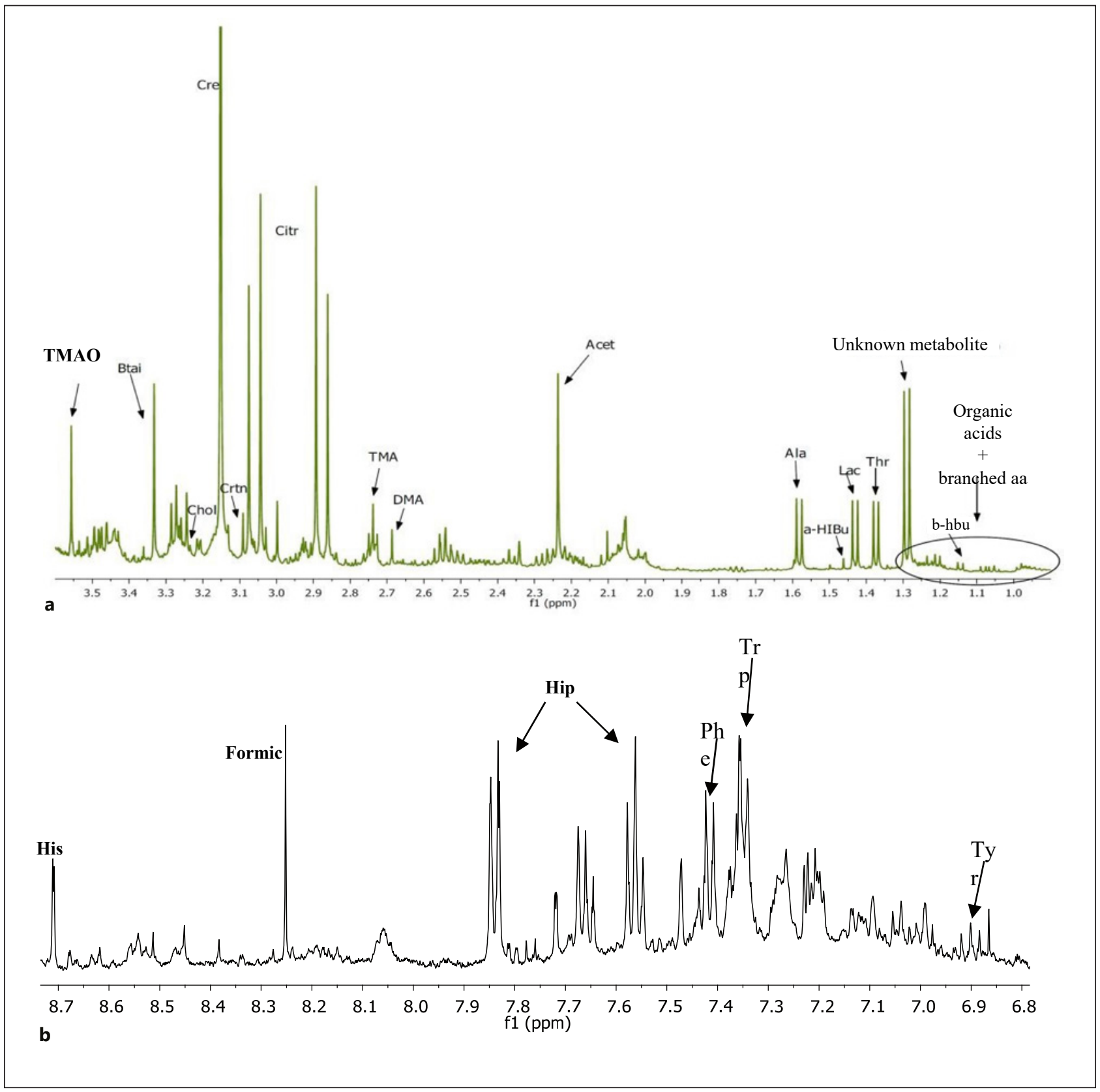

Fig. 4. ${ }^{1} \mathrm{H}-\mathrm{NMR}$ spectrum of a thalassemic patient zoomed in the 0.8-3.6 ppm (a) and 6.7-8.7 ppm (b) spectral ranges. Some of the peaks are labeled with the respective over- and underexcreted metabolite. b-HBu, $\beta$-hydroxybutyric acid; Thr, threonine; Lac, lactate; b-a-HIBu, $\beta$-hydroxyisobutyric acid; Ala, alanine; Acet, acetone; DMA, dimethylamine; TMA, trimethylamine; Citr, citrate; Crtn, carnitine; Cre, creatine; Chol, choline; Btai, betaine; TMAO, trimethylamino-N-oxide; Hipp, hippuric acid; Form, formic acid; His, histidine; Trp, triptophane; Tyr, tyrosine; Phe, phenyalanine.

Visual inspection of the spectra of the thalassemic patients shows a very crowded spectral region in the low range of $1-3.5 \mathrm{ppm}$ (Fig. 4). In this range, the peaks of amino acids with lateral alkyl chains and of most of the low-molecular weight organic acids, are under resonance, together with the characteristic singlets of $\mathrm{N}$-alkyl metabolites such as TMAO, betaine, taurine, carnitine, etc. (Fig. 4). On the other hand, the high range of 7-8 ppm contains the 
Capolongo et al.: Urinary Metabolomics in $\beta$-TM

Table 2. Univariate statistics of a selected list of metabolites which drive the discrimination between the $\beta$-TM and age- and gender-matched control populations

\begin{tabular}{|c|c|c|c|}
\hline \multirow[t]{2}{*}{ Metabolite } & \multicolumn{2}{|c|}{$\begin{array}{l}\text { Metabolite median concentration }{ }^{1} \text {, } \\
\mathrm{mmol} / \mathrm{mol}\end{array}$} & \multirow[t]{2}{*}{$p$ value $^{2}$} \\
\hline & $\beta$-ТM & controls & \\
\hline Valine & 2.9 & 1.6 & 0.00006 \\
\hline Threonine & 33.9 & 14.0 & 0.0009 \\
\hline Alanine & 61.2 & 32.8 & 0.000002 \\
\hline Acetic acid & 20.4 & 9.4 & 0.0003 \\
\hline Citric acid & 578.9 & 442.3 & 0.035 \\
\hline Taurine & 69.1 & 47.8 & 0.00006 \\
\hline Carnitine & 5.6 & 2.6 & 0.0002 \\
\hline TMAO & 55.1 & 51.9 & 0.3 \\
\hline Betaine & 20.2 & 6.9 & 0.00005 \\
\hline Glycine & 221.0 & 72.5 & 0.000006 \\
\hline Hippuric acid & 55.2 & 110.5 & 0.0007 \\
\hline Formic acid & 140.5 & 38.8 & 0.00000000003 \\
\hline b-hbu & 7.9 & 8.4 & 0.4 \\
\hline Unknown & 109.9 & 12.3 & 0.00000002 \\
\hline
\end{tabular}

peaks of some other amino acids like histidine, phenylalanine, triptophane, tyrosine, and other organic acids like hippuric and formic acid.

Even though the metabonomics analysis revealed that the difference in the urinary metabolite profile between the $\beta$-TM and control populations was due to a significant different multiparametric response, the concentrations of some selected metabolites were differentially excreted in the urine. Online supplementary Tables S1 and S2 list several metabolites that are more or less abundant in the urine of patients than in controls. Interestingly, a number of molecules known to be reabsorbed along the proximal tubule, e.g., amino acids (valine, threonine, and alanine) and citrate, were overexcreted in the $\beta$-TM patients, suggesting a tubular defect.

Notably, Figure 4 also shows the presence, in all thalassemic samples, of a doublet at $1.282-1.297 \mathrm{ppm}$. In contrast, $>10 \%$ of the healthy samples did not show the above signal, and the mean concentration in the control population is significantly lower than in the $\beta$-TM subjects (Table 2). Indeed, this metabolite is one of the most important factors contributing to the distinction between healthy and $\beta$-TM individuals (Fig. 2, 3). A 2-dimensional NMR correlation spectroscopy (COSY) study was performed to detect spectral signatures related to this doublet. This analysis revealed that the doublet was linked to several low-intensity peaks in the region of 2.5 and $3.5 \mathrm{ppm}$. This finding suggests that one of the candidate molecular structures could be a derivative of 2-(1-hydoxyethyl)propanedioc acid. Further investigations are needed to definitely assign the above signal.

\section{Discussion}

The major new finding in this study is that $\beta$-TM patients undergoing transfusions and DFX therapy versus normal individuals exhibit different concentrations of some metabolites in the urine. Our data show that $\mathrm{N}$-methyl compounds and organic acids were overexcreted 
in the urine of thalassemic patients compared with controls. Moreover, a number of molecules normally reabsorbed along the proximal tubule, like valine, threonine, and alanine as well as citrate, are overexcreted in $\beta$-TM patients, suggesting a tubular defect of this tract of the nephron. These results further support the hypothesis that "urinomic" analysis may be potentially used for the early detection of renal dysfunction in this setting.

The pathogenesis of kidney damage in $\beta$-TM is currently unknown and requires additional studies. In our study cohort, we found a high incidence of low-molecular-weight proteinuria and defective urine concentration in the $\beta$-TM subjects. Selected patients, those on DFX, had urine osmolality $<750$ and $<600 \mathrm{m0sm} / \mathrm{kg}$ (adults and children, respectively), and thus differed significantly from controls. $\beta$-TM patients also had a tendency towards more alkaline urinary $\mathrm{pH}$. This seems not to depend on the loss of bicarbonate $\left(\mathrm{FeHCO}_{3}<1 \%\right)$ or phosphate in the urine but is rather related to the increased urine excretion of organic anions. Indeed, this altered the urinary buffer capacity (increasing the titratable acidity), influencing the $12 \mathrm{~h}$ night-fasting urinary acid excretion. Moreover, $60 \%$ of the patients had hypercalciuria but not hypercalcemia, as previously reported [10, 48].

In line with our data, several other reports have shown that $\beta$-TM is associated with renal dysfunction [27-29]. Renal manifestations in $\beta$-TM have a multifactorial genesis related to the natural history of the disease: chronic anemia, potential associated chronic hypoxia, iron overload, and the use of specific iron chelators [27]. Şen et al. [30] suggested that urinary NAG and NGAL may be considered reliable markers for monitoring renal injury in $\beta$-TM patients. Chronic anemia and hypoxia are also associated with oxidative stress, lipid peroxidation, and functional abnormalities in tubular cells. There is evidence in the literature of a significant correlation between the severity of anemia and markers of tubular abnormalities in patients with $\beta$-TM. The underlying pathophysiological mechanism is considered multifactorial, including increased vascular resistance, with consequent hyperdynamic circulation and modulation of the renal plasma flow and GFR [31,32].

Reports of kidney injury in $\beta$-TM patients demonstrate an association between proximal tubular dysfunction and intracellular iron deposition [33, 34]. Experimental studies on an animal model of $\beta$-TM exposed to chronic iron loading showed that rats developed iron deposits in glomeruli and in the proximal but not distal tubules, with signs of significant glomerulosclerosis, tubular atrophy, and interstitial fibrosis [35]. In the acidic proximal tubular fluid, iron dissociates from transferrin and induces the production of reactive oxygen species, with subsequent damage to the brush-border of the renal tubular membrane [36]. Moreover, the use of iron-chelating agents has been associated with renal toxicity in patients with transfusion-dependent $\beta$-TM and iron overload [37,38]. DFX forms complexes with iron and promotes its excretion, but it is not indicated for creatinine clearance $<40 \mathrm{~mL} / \mathrm{min} / 1.73$ $\mathrm{m}^{2}$ or serum creatinine $>2$ times the upper limit of normal [39]. In this study, all patients had an eGFR $>60 \mathrm{ml} / \mathrm{min} / 1.73 \mathrm{~m}^{2}$ and were treated with DFX for $>12$ months.

"Omics" technologies are a novel and expanding area in clinical research and are emerging as diagnostic and therapeutic tools in many inherited renal and extrarenal diseases [40-42, 49]. The application of multi-omics studies to investigate genetic rare diseases offers the possibility of understanding the pathophysiological mechanisms underlying kidney dysfunction [43]. In addition, urine is a biological sample that is easy to collect in a noninvasive manner, providing the possibility of carefully identifying thousands of renal and extrarenal molecules [44]. Early and accurate identification of urinary markers could be useful for assessing initial damage to tubules, and possibly improve the management of rare renal disease and its progression to the end stage, i.e., chronic kidney disease [45]. The application of metabolomics, the large-scale study of small molecules, metabolomes, and their interaction with the biological system and environment, may improve our knowledge in this field of research [46]. 


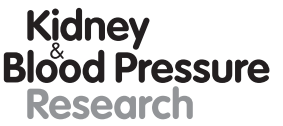

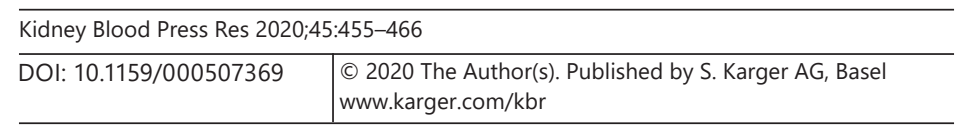

Capolongo et al.: Urinary Metabolomics in $\beta$-TM

To date, there is little information on the pathogenesis, risk, and predictors of poor renal outcome in $\beta$-TM. This is the first experimental study on metabolomics in thalassemic patients. Our results show that $\beta$-TM subjects undergoing transfusions and DFX therapy have some metabolites overexcreted in their urine.

One limitation of the study is that any change in the urine metabolite profile could be associated with any of the following: thalassemia, transfusions, DFX therapy, or a combination, with no way of discerning which. However, our results support other studies by showing that tubular dysfunction is common in $\beta$-TM. We demonstrated that tubular defects may be revealed by a complex urinary metabolic multiparametric response. In our opinion, these findings can be used to possibly identify patients in an early stage of renal failure. Further studies may investigate the effect of different chelating agents on the urinary metabolite profile of thalassemic individuals.

Another limitation is that our findings were based on a cross-sectional observation. Longitudinal studies are needed to better address the mechanisms underlying renal dysfunction in $\beta$-TM and whether the metabolomic patterns may characterize patients with a higher risk of kidney disease progression.

A precision medicine approach will allow us to tailor counseling, screening, treatment recommendations, and the early individuation of markers of renal dysfunction so as to be able to prevent the evolution of kidney disease in this setting.

\section{Statement of Ethics}

The study protocol was approved by the "Cardarelli- Santobono" Ethics Committee (protocol No. 1795) and conducted according to the principles of the Declaration of Helsinki and Good Clinical Practice. All participants signed an informed consent document.

\section{Disclosure Statement}

The authors have no conflicts of interest to disclose.

\section{Funding Sources}

This study was funded by Novartis Farma SpA.

\section{Author Contributions}

Conceptualization: G. Capolongo, M. Zacchia; methodology: A. Filosa, G. Capasso; formal analysis and investigation: A. Beneduci, G. De Luca, M.E. Di Pietro; preparation of the original draft: G. Capolongo, A. Beneduci; review and editing of the article: G. Capolongo, M. Zacchia, F. Trepiccione; resources: S. Costantini, P. Ricchi, P. Cinque, A. Spasiano, F. Trepiccione; supervision: G. Capasso. 


\begin{tabular}{l|l}
\hline \multicolumn{2}{l}{ Kidney Blood Press Res 2020;45:455-466 } \\
\hline DOI: 10.1159/000507369 & $\begin{array}{l}\text { (c) 2020 The Author(s). Published by S. Karger AG, Basel } \\
\text { www.karger.com/kbr }\end{array}$ \\
\hline
\end{tabular}

Capolongo et al.: Urinary Metabolomics in $\beta$-TM

\section{References}

1 Borgna-Pignatti C, Rugolotto S, De Stefano P, Zhao H, Cappellini MD, Del Vecchio GC, et al. Survival and complications in patients with thalassemia major treated with transfusion and deferoxamine. Haematologica. 2004 Oct;89(10):1187-93.

2 Hashemieh M, Azarkeivan A, Akhlaghpoor S, Shirkavand A, Sheibani K. T2-star (T2*) magnetic resonance imaging for assessment of kidney iron overload in thalassemic patients. Arch Iran Med. 2012;15(2):91-4.

3 Azarkeivan A, Hashemieh M, Shirkavand A, Sheibani K. Correlation between Heart, Liver and Pancreas Hemosiderosis Measured by MRI T2* among Thalassemia Major Patients from Iran. Arch Iran Med. 2016;19(2): 96-100.

4 Bakr A, Al-Tonbary Y, Osman G, El-Ashry R. Renal complications of beta-thalassemia major in children. Am J Blood Res. 2014 Sep;4(1):1-6.

5 Tantawy AA, El Bablawy N, Adly AA, Ebeid FS. Early Predictors of Renal Dysfunction in Egyptian Patients with $\beta$-Thalassemia Major and Intermedia. Mediterr J Hematol Infect Dis. 2014 Sep;6(1):e2014057.

6 Quinn CT, Johnson VL, Kim HY, Trachtenberg F, Vogiatzi MG, Kwiatkowski JL, et al.; Thalassemia Clinical Research Network. Renal dysfunction in patients with thalassaemia. Br J Haematol. 2011 Apr;153(1):111-7.

7 Piga A, Fracchia S, Lai ME, Cappellini MD, Hirschberg R, Habr D, et al. Deferasirox effect on renal haemodynamic parameters in patients with transfusion-dependent $\beta$ thalassaemia. Br J Haematol. 2015 Mar;168(6):882-90.

8 Milat F, Wong P, Fuller PJ, Johnstone L, Kerr PG, Doery JC, et al. A case of hypophosphatemic osteomalacia secondary to deferasirox therapy. J Bone Miner Res. 2012 Jan;27(1):219-22.

9 Naderi M, Sadeghi-Bojd S, Valeshabad AK, Jahantigh A, Alizadeh S, Dorgalaleh A, et al. A prospective study of tubular dysfunction in pediatric patients with Beta thalassemia major receiving deferasirox. Pediatr Hematol Oncol. 2013 Nov;30(8):748-54.

10 Wong P, Polkinghorne K, Kerr PG, Doery JC, Gillespie MT, Larmour I, et al. Deferasirox at therapeutic doses is associated with dose-dependent hypercalciuria. Bone. 2016 Apr;85:55-8.

11 Papassotiriou I, Margeli A, Hantzi E, Delaporta P, Sergounioti A, Goussetis E, et al. Cystatin C levels in patients with beta-thalassemia during deferasirox treatment. Blood Cells Mol Dis. 2010 Mar;44(3):152-5.

12 Voskaridou E, Terpos E, Michail S, Hantzi E, Anagnostopoulos A, Margeli A, et al. Early markers of renal dysfunction in patients with sickle cell/beta-thalassemia. Kidney Int. 2006 Jun;69(11):2037-42.

13 Ricchi P, Ammirabile M, Spasiano A, Costantini S, Di Matola T, Cartenì G, et al. Renal cell carcinoma in adult patients with thalassaemia major: a description of three cases. Br J Haematol. 2014 Jun;165(6):887-8.

14 Ricchi P, Meloni A, Grigoratos C, Toia P, Fina P, Pistoia L, et al. Prevalence of extramedullary hematopoiesis, renal cysts, splenic and hepatic lesions, and vertebral hemangiomas among thalassemic patients: a retrospective study from the Myocardial Iron Overload in Thalassemia (MIOT) network. Ann Hematol. 2019 Jun; 98(6):1333-9.

15 Saccà F, Puorro G, Brunetti A, Capasso G, Cervo A, Cocozza S, et al. A randomized controlled pilot trial of lithium in spinocerebellar ataxia type 2. J Neurol. 2015 Jan;262(1):149-53.

16 Capolongo G, Sakhaee K, Pak CY, Maalouf NM. Fasting versus 24-h urine $\mathrm{pH}$ in the evaluation of nephrolithiasis. Urol Res. 2011 Oct;39(5):367-72.

17 Trepiccione F, Iena FM, Catalini L, Carpi FM, Koed M, Frische S. Measurement of total CO2 in microliter samples of urine and other biological fluids using infrared detection of C02. Pflugers Arch. 2017 0ct;469(10):1267-75.

18 Trepiccione F, Altobelli C, Capasso G, Christensen BM, Frische S. Lithium increases ammonium excretion leading to altered urinary acid-base buffer composition. J Nephrol. 2018 Jun;31(3):385-93.

19 Levin A, Stevens PE. Summary of KDIGO 2012 CKD Guideline: behind the scenes, need for guidance, and a framework for moving forward. Kidney Int. 2014 Jan;85(1):49-61.

20 Beneduci A, Cuccurullo M, Pontoni G, Chidichimo G, Capasso G. Perspectives of 1H-NMR-based urinary metabonomics in Fabry disease. J Nephrol. 2010 Nov-Dec;23 Suppl 16:S213-20.

21 Beneduci A, Chidichimo G, Dardo G, Pontoni G. Highly routinely reproducible alignment of 1H NMR spectral peaks of metabolites in huge sets of urines. Anal Chim Acta. 2011 Jan;685(2):186-95.

22 D’Adamo P, Ulivi S, Beneduci A, Pontoni G, Capasso G, Lanzara C, et al. Metabonomics and population studies: age-related amino acids excretion and inferring networks through the study of urine samples in two Italian isolated populations. Amino Acids. 2010 Jan;38(1):65-73.

23 Xiao C, Hao F, Qin X, Wang Y, Tang H. An optimized buffer system for NMR-based urinary metabonomics with effective pH control, chemical shift consistency and dilution minimization. Analyst (Lond). 2009 May;134(5): 916-25.

24 Ross A, Schlotterbeck G, Dieterle F, Senn H. Chapter 3: NMR spectroscopy techniques for application to metabonomics. In: Lindon JC, Nicholson JK, Holmes E, editors. The Handbook of Metabonomics and Metabolomics. Elsevier; 2006. pp. 55-112.

25 Zacchia M, Capolongo G, Rinaldi L, Capasso G. The importance of the thick ascending limb of Henle's loop in renal physiology and pathophysiology. Int J Nephrol Renovasc Dis. 2018 Feb;11:81-92.

26 Zacchia M, Zacchia E, Zona E, Capolongo G, Raiola I, Rinaldi L, et al. Renal phenotype in Bardet-Biedl syndrome: a combined defect of urinary concentration and dilution is associated with defective urinary AQP2 and UMOD excretion. Am J Physiol Renal Physiol. 2016 Oct;311(4):F686-94.

27 Demosthenous C, Vlachaki E, Apostolou C, Eleftheriou P, Kotsiafti A, Vetsiou E, et al. Beta-thalassemia: renal complications and mechanisms: a narrative review. Hematology. 2019 Dec;24(1):426-38. 
28 Nickavar A, Qmarsi A, Ansari S, Zarei E. Kidney Function in Patients With Different Variants of Beta-Thalassemia. Iran J Kidney Dis. 2017 Mar;11(2):132-7.

29 Sadeghi-Bojd S, Hashemi M, Karimi M. Renal tubular function in patients with beta-thalassaemia major in Zahedan, southeast Iran. Singapore Med J. 2008 May;49(5):410-2.

30 Șen V, Ece A, Uluca Ü, Söker M, Güneș A, Kaplan İ, et al. Urinary early kidney injury molecules in children with beta-thalassemia major. Ren Fail. 2015 May;37(4):607-13.

31 Patsaoura A, Tatsi E, Margeli A, Kanavaki I, Delaporta P, Kyriakopoulou D, et al. Plasma neutrophil gelatinaseassociated lipocalin levels are markedly increased in patients with non-transfusion-dependent thalassemia: lack of association with markers of erythropoiesis, iron metabolism and renal function. Clin Biochem. 2014 Aug;47(12):1060-4.

32 Roudkenar MH, Halabian R, Oodi A, Roushandeh AM, Yaghmai P, Najar MR, et al. Upregulation of neutrophil gelatinase-associated lipocalin, NGAL/Lcn2, in beta-thalassemia patients. Arch Med Res. 2008 May;39(4): $402-7$.

33 Lafferty HM, Anderson S, Brenner BM. Anemia: a potent modulator of renal hemodynamics in models of progressive renal disease. Am J Kidney Dis. 1991 May;17(5 Suppl 1):2-7.

34 Davis LE, Hohimer AR. Hemodynamics and organ blood flow in fetal sheep subjected to chronic anemia. Am J Physiol. 1991 Dec;261(6 Pt 2):R1542-8.

35 Yatmark P, Morales NP, Chaisri U, Wichaiyo S, Hemstapat W, Srichairatanakool S, et al. Iron distribution and histopathological study of the effects of deferoxamine and deferiprone in the kidneys of iron overloaded $\beta$-thalassemic mice. Exp Toxicol Pathol. 2016 Sep;68(8):427-34.

36 Alfrey AC. Role of iron and oxygen radicals in the progression of chronic renal failure. Am J Kidney Dis. 1994 Feb;23(2):183-7.

37 Taher AT, Saliba AN, Kuo KH, Giardina PJ, Cohen AR, Neufeld EJ, et al. Safety and pharmacokinetics of the oral iron chelator SP-420 in $\beta$-thalassemia. Am J Hematol. 2017 Dec;92(12):1356-61.

38 Chuang GT, Tsai IJ, Tsau YK, Lu MY.Transfusion-dependent thalassaemic patients with renal Fanconi syndrome due to deferasirox use. Nephrology (Carlton). 2015 Dec;20(12):931-5.

39 Dee CM, Cheuk DK, Ha SY, Chiang AK, Chan GC. Incidence of deferasirox-associated renal tubular dysfunction in children and young adults with beta-thalassaemia. Br J Haematol. 2014 Nov;167(3):434-6.

40 Capolongo G, Zacchia M, Perna A, Viggiano D, Capasso G. Urinary proteome in inherited nephrolithiasis. Urolithiasis. 2019 Feb; 47(1):91-8.

41 Costanzo M, Zacchia M, Bruno G, Crisci D, Caterino M, Ruoppolo M. Integration of Proteomics and Metabolomics in Exploring Genetic and Rare Metabolic Diseases. Kidney Dis. 2017 Jul;3(2):66-77.

42 Zacchia M, Vilasi A, Capasso A, Morelli F, De Vita F, Capasso G. Genomic and proteomic approaches to renal cell carcinoma. J Nephrol. 2011 Mar-Apr;24(2):155-64.

43 Zacchia M, Marchese E, Trani EM, Caterino M, Capolongo G, Perna A, et al. Proteomics and metabolomics studies exploring the pathophysiology of renal dysfunction in autosomal dominant polycystic kidney disease and other ciliopathies. Nephrol Dial Transplant. 2019. DOI:10.1093/ndt/gfz121.

44 Imperlini E, Santorelli L, Orrù S, Scolamiero E, Ruoppolo M, Caterino M. Mass Spectrometry-Based Metabolomic and Proteomic Strategies in Organic Acidemias. BioMed Res Int. 2016;2016:9210408.

45 Mullen W, Delles C, Mischak H; EuroKUP COST action. Urinary proteomics in the assessment of chronic kidney disease. Curr Opin Nephrol Hypertens. 2011 Nov;20(6):654-61.

46 Scolamiero E, Cozzolino C, Albano L, Ansalone A, Caterino M, Corbo G, et al. Targeted metabolomics in the expanded newborn screening for inborn errors of metabolism. Mol Biosyst. 2015 Jun;11(6):1525-35.

47 Trepiccione F, Zacchia M, Capasso G. The role of the kidney in salt-sensitive hypertension. Clin Exp Nephrol. 2012 Feb;16(1):68-72.

48 Petrazzuolo 0, Trepiccione F, Zacchia M, Capasso G. Hypertension and renal calcium transport. J Nephrol. 2010;23(Suppl 16):S112-7.

49 Matafora V, Zagato L, Ferrandi M, Molinari I, Zerbini G, Casamassima N, et al. Quantitative proteomics reveals novel therapeutic and diagnostic markers in hypertension. BBA Clin. 2014 Oct;2:79-87. 